\title{
Serum-borne factors alter cerebrovascular endothelial microRNA expression following particulate matter exposure near an abandoned uranium mine on the Navajo Nation
}

Bethany Sanchez ${ }^{1}$, Xixi Zhou', Amy S. Gardiner², Guy Herbert' ${ }^{1}$, Selita Lucas', Masako Morishita ${ }^{3}$, James G. Wagner ${ }^{4}$, Ryan Lewandowski ${ }^{4}$, Jack R. Harkema ${ }^{4}$, Chris Shuey ${ }^{5}$, Matthew J. Campen ${ }^{1}$ and Katherine E. Zychowski ${ }^{6^{*}}$

\begin{abstract}
Background: Commercial uranium mining on the Navajo Nation has subjected communities on tribal lands in the Southwestern United States to exposures from residual environmental contamination. Vascular health effects from these ongoing exposures are an active area of study. There is an association between residential mine-site proximity and circulating biomarkers in residents, however, the contribution of mine-site derived wind-blown dusts on vascular and other health outcomes is unknown. To assess neurovascular effects of mine-site derived dusts, we exposed mice using a novel exposure paradigm, the AirCARE1 mobile inhalation laboratory, located $2 \mathrm{~km}$ from an abandoned uranium mine, Claim 28 in Blue Gap Tachee, AZ. Mice were exposed to filtered air (FA) $(n=6)$ or concentrated ambient particulate matter (CAPs) $(n=5)$ for 2 wks for $4 \mathrm{~h}$ per day.

Results: To assess miRNA differential expression in cultured mouse cerebrovascular cells following particulate matter (PM) exposure (average: $96.6 \pm 60.4 \mu \mathrm{g} / \mathrm{m}^{3}$ for all $4 \mathrm{~h}$ exposures), the serum cumulative inflammatory potential (SCIP) assay was employed. MiRNA sequencing was then performed in cultured mouse cerebrovascular endothelial cells (mCECs) to evaluate transcriptional changes. Results indicated 27 highly differentially expressed $(p<0.01)$ murine miRNAs, as measured in the SCIP assay. Gene ontology $(\mathrm{GO})$ pathway analysis revealed notable alterations in GO enrichment related to the cytoplasm, protein binding and the cytosol, while significant KEGG pathways involved pathways in cancer, axon guidance and Wnt signaling. Expression of these 27 identified, differentially expressed murine miRNAs were then evaluated in the serum. Nine of these miRNAs $(\sim 30 \%)$ were significantly altered in the serum and 8 of those miRNAs demonstrated the same directional change (either upregulation or downregulation) as cellular miRNAs, as measured in the SCIP assay. Significantly upregulated miRNAs in the CAPs exposure group included miRNAs in the let-7a family. Overexpression of mmu-let-7a via transfection experiments, suggested that this miRNA may mediate mCEC barrier integrity following dust exposure.

(Continued on next page)
\end{abstract}

\footnotetext{
* Correspondence: KZychowski@salud.unm.edu

${ }^{6}$ College of Nursing, MSC09 53601 University of New Mexico-Health Sciences Center, Albuquerque, NM 87131, USA

Full list of author information is available at the end of the article
}

C C The Author(s). 2020 Open Access This article is licensed under a Creative Commons Attribution 4.0 International License, which permits use, sharing, adaptation, distribution and reproduction in any medium or format, as long as you give appropriate credit to the original author(s) and the source, provide a link to the Creative Commons licence, and indicate if changes were made. The images or other third party material in this article are included in the article's Creative Commons licence, unless indicated otherwise in a credit line to the material. If material is not included in the article's Creative Commons licence and your intended use is not permitted by statutory regulation or exceeds the permitted use, you will need to obtain permission directly from the copyright holder. To view a copy of this licence, visit http://creativecommons.org/licenses/by/4.0/. The Creative Commons Public Domain Dedication waiver (http://creativecommons.org/publicdomain/zero/1.0/) applies to the data made available in this article, unless otherwise stated in a credit line to the data. 


\begin{abstract}
(Continued from previous page)
Conclusions: Our data suggest that mCEC miRNAs as measured in the SCIP assay show similarity to serum-borne miRNAs, as approximately $30 \%$ of highly differentially expressed cellular miRNAs in the SCIP assay were also found in the serum. While translocation of miRNAs via exosomes or an alternative mechanism is certainly possible, other yet-to-be-identified factors in the serum may be responsible for significant miRNA differential expression in endothelium following inhaled exposures. Additionally, the most highly upregulated murine miRNAs in the CAPs exposure group were in the let-7a family. These miRNAs play a prominent role in cell growth and differentiation and based on our transfection experiments, mmu-let-7a may contribute to cerebrovascular mCEC alterations following inhaled dust exposure.
\end{abstract}

Keywords: Endothelial, $\mathrm{PM}_{2.5}$, microRNAs, Serum, Mmu-let-7a, Blood-brain barrier, Uranium

\section{Introduction}

Commercial uranium mining was active on the Navajo Nation from the 1940s-1980s during the Cold War era [1-3]. As a result of commercial uranium mining and insufficient remediation, many tribal communities located in the Southwestern United States are exposed to varying degrees of contaminant metal mixtures arising from abandoned uranium mines (AUMs) [4-6]. Exposure to metals through drinking water has been linked to adverse health outcomes [7-10], and residential proximity to AUMs is associated with an increase in circulating inflammatory biomarkers [11]. However, the contribution of wind-blown dust exposure on vascular and other health outcomes remains unclear. Moreover, there is a lack of consensus in the literature regarding how to evaluate vascular outcomes following $\mathrm{PM}_{2.5}$ exposure $[12,13]$. Classical biomarkers of ingestion-related metals-exposure typically included assessment of metal concentration in the urine and blood [14]. However, metal levels detected in these biofluids do not necessarily translate to a specific pathological outcome, therefore assessing alternative molecular biomarkers of exposure may be warranted.

Residential proximity to AUMs is significantly associated with cumulative circulating inflammatory potential in the serum of local residents, as determined by an ex vivo mCEC cell bioassay, the serum cumulative inflammatory potential (SCIP) assay, developed in our laboratory $[6,11,15,16]$. The SCIP assay is used to assess mCEC cellular mRNA and protein responses to circulating serum-borne ligands following inhaled toxicant exposure or environmental insult [15-20]. This assay has detected variations of mRNA and protein expression between control and exposed groups. Differential expression of mCEC cellular microRNAs (miRNAs) as measured in the SCIP assay have yet to be explored.

MiRNAs are small non-coding RNAs responsible for silencing gene expression. They are roughly 22 base pairs long and originate in the nucleus of the cell, but can also be found in the extracellular environment in various biological fluids including serum [21], interstitial fluid [22-24], and urine [25-27]. More recently, circulating miRNAs have been utilized as biomarkers of environmental and toxicological exposure [21, 28], with documented associations between metal exposure and circulating miRNAs [29-31]. MiRNAs also play a key role in regulating neuroinflammation and the bloodbrain barrier (BBB) [32, 33]. Recent research from our group indicates that inhaled pollutants prompt a systemic inflammatory response resulting in $\mathrm{mCEC}$ dysfunction, a key feature of BBB disruption [34-36]. Compromising the $\mathrm{BBB}$ via inhaled toxicant exposure may potentiate preexisting vulnerability to a neurovascular event such as a stroke or aneurysm rupture [37, 38]. Additionally, air pollution has been implicated in neuroinflammation and diseases of the central nervous system [39-41]. While the molecular mechanisms underlying air pollution-induced neurological outcomes are unclear, one current hypothesis is that peptide fragments shed from the lung following inhaled pollutant exposures induce mCEC dysfunction via scavenger receptors [17, 34, 42]. Recent studies, using the SCIP assay following pulmonary exposure to multiwalled nanomaterials, highlight extensive peptidomic changes to the serum composition that align with changes in the serum bioactivity [43]. Nanotube exposure induces elevations in circulating peptides that appear to arise from endogenous proteins, with the hypothesis that matrix metalloproteinase (MMP) activation in the lung may trigger the generation of circulating fragmented peptides. These peptides, in turn, have a retained cumulative bioactivity on the endothelium that may impair barrier integrity and vasodilatory pathways.

In an effort to more thoroughly characterize the burden of wind-blown dust-driven health effects in this region, more specifically, neurovascular dysfunction, we exposed mice to ambient on-site PM using a mobile air research laboratory, AirCARE1 near an AUM, Claim 28, in the central region of Navajo Nation. MiRNA sequencing was performed in mCECs treated with serum from exposed mice (SCIP assay) to evaluate transcriptional changes and the most significantly altered murine cellular miRNAs were then assessed in the serum. One 
highly-upregulated miRNA in the CAPs exposure group (mmu-let-7a), was transfected in cultured mCECs in vitro using the SCIP assay and endothelial barrier integrity endpoints were assessed. In this exploratory study, we hypothesized that exposure to CAPs induces circulating factors that drive differential mCEC miRNA differential expression, as characterized in the SCIP assay. To our knowledge, this is the first assessment of mCEC miRNA alterations, as a result of serum-borne factors from mice exposed to FA and CAPs.

\section{Methods and materials \\ Study site}

Deployment of AirCARE1 was executed in Blue Gap Tachee, AZ, roughly $2 \mathrm{~km}$ away from the Claim 28 mine site on the Navajo Nation Reservation. Wind speed and direction were collected at 15-min intervals using meteorological stations (WindLog, RainWise, Inc., Trenton, ME, USA) placed on the roof of AirCARE1 and on the mesa ridge of the mine site during the course of the exposure.

\section{AirCARE1 inhalation laboratory exposure paradigm}

Michigan State University's AirCARE1, a mobile inhalation toxicology laboratory constructed within a renovated 53' semitrailer, utilizes a Harvard fine-type particle concentrator to expose animals to ambient onsite PM in tandem with real-time PM monitoring. The fine particle concentrator performance and the exposure systems in AirCARE1 have been described in detail previously $[44,45]$. Exposures were executed $4 \mathrm{~h}$ per day for 15 consecutive days in November/December 2017. Sixeight wk. old C57BL/6 male mice (Taconic, Rensselaer, $\mathrm{NY}$ ) were randomly assigned to either filtered air (FA, $n=6)$ or particulate matter $<2.5 \mathrm{~m}$ (CAPs, $n=5)$ exposure. Immediately after the mice were loaded into the chambers, the doors were sealed. Animals were placed in Hinners stainless steel, whole-body exposure chambers to acclimate roughly $1 \mathrm{~h}$ prior to the start of the exposure. Exposures started at $9 \mathrm{AM}$ and continued until $1 \mathrm{PM}$. Monitoring ensured a flow rate of $50 \mathrm{~L} / \mathrm{min}$ at 0.94-0.95 atm. The PM mass was collected on $47-\mathrm{mm}$ Teflon (PTFE) filters (Gelman Science) in Teflon/Teflon-coated filter packs attached to the side of the exposure chamber. A Sidepak Personal Aerosol Monitor (TSI, Shoreview, MN, USA) was used to measure real-time PM in the exposure chambers; final gravimetric concentrations derived from filter weights (as described below) were used as the actual mass concentration assessment. The pressure in the FA chamber was adjusted to the same level in the CAPs chamber (0.94-0.95 atm). HEPA-filtered room air (maintained at $21^{\circ} \mathrm{C}$ and $60 \pm$ $10 \%$ relative humidity) was supplied to the control chamber at $50 \mathrm{~L} / \mathrm{min}$. Meteorological endpoints including temperature, wind speed and direction were all collected in real-time. Following the end of exposures, the chamber was switched back to FA and the pressure in both exposure chambers was raised to atmospheric pressure. Food and water were provided following the exposures, as per IACUC protocol. Mice were transported to the University of New Mexico following the end of exposures and euthanized for tissue collection and downstream analyses $24 \mathrm{~h}$ later.

\section{Particulate elemental composition analysis}

The Teflon filter samples were shipped to the Michigan State University Exposure Science Laboratory and subsequently processed and analyzed in their Class 100 clean room. The gravimetric mass concentrations were determined from the filters using a microbalance (XP6; Mettler-Toledo) in a temperature- and humiditycontrolled clean room as described in the EPA Federal Reference Method. Following the gravimetric analysis, the Teflon filters were analyzed for trace metals. The Teflon filters were placed in $15 \mathrm{~mL}$ centrifuge tubes and moistened with 150 /L of ethanol before extraction in $10 \mathrm{~mL}$ of $1 \% \mathrm{HNO}_{3}$. The $1 \% \mathrm{HNO}_{3}$ solution was then sonicated in an ultrasonic bath for $48 \mathrm{~h}$ and used to passively digest the filter for 2 wks. Sample extracts were then analyzed for selected trace elements using highresolution inductively coupled plasma mass spectrometry (ICP-MS, ELEMENT2, Thermo Finnigan, San Jose, CA). Commercially available multi-element standards were used to create a standard curve in a $1 \% \mathrm{HNO}_{3}$ solution and the matrix was matched with the samples. The $R^{2}$ value was determined for each element via ELEMENT software. Data including daily QA/QC measurements such as field blanks, acid blanks, laboratory blanks and replicate analyses were matched with the samples. Standards were analyzed as samples to evaluate instrument stability and the National Institute of Standards and Technology (NIST, Gaithersburg, MD) Standard Reference Material 1640A was used as a quality control standard.

\section{Bronchoalveolar lavage fluid analysis}

Mice were euthanized $24 \mathrm{~h}$ post-CAPs exposure. Mice were sedated with $5 \%$ isoflurane at a rate of $5 \mathrm{~L} / \mathrm{min}$ until unresponsive, and subsequently subjected to cardiac puncture and exsanguination. Bronchoalveolar lavage fluid (BALF) analysis was performed following euthanasia by puncturing the trachea and intubating each mouse using a 20-gauge cannula. One $\mathrm{mL}$ of PBS was then injected into the lungs and pulled out following inflation. Total BALF cells, macrophages and neutrophils were counted using a hemocytometer and stained with Trypan Blue (Thermo Fisher Scientific, Waltham, MA, 
USA) to determine viability. BALF was then centrifuged at $500 \mathrm{x} \mathrm{g}$ for $10 \mathrm{~min}$ at $4{ }^{\circ} \mathrm{C}$ and supernatants were collected and analyzed. BALF supernatant total protein was assessed using a bicinchoninic acid (BCA) assay [46] and read at an absorbance of $595 \mathrm{~nm}$ using a Tecan plate reader (Tecan, Mannedorf, Switzerland).

\section{Cell culture}

Mouse cerebrovascular endothelial cells were grown to approximately $80 \%$ confluence as per the manufacturer's instructions (Lonza, Basel, Switzerland). Flasks were coated with poly-l-lysine prior to plating. Basal complete media was replaced every other day and cells were passaged once per week.

\section{Serum cumulative inflammatory potential (SCIP) bioassay} Mouse cerebrovascular endothelial cells (mCECs) (Lonza, Allendale, NJ) were seeded in a 24-well plate and grown to confluence in complete media (Lonza). In total, 11 samples were analyzed with 6 biological replicates in the FA group and 5 biological replicates in the CAPs group. Cells were serum-starved for $24 \mathrm{~h}$ prior to exposure, to synchronize all of the cells to the same cell cycle phase. Confluent mCECs were incubated with serum from CAPs-exposed mice and FA-exposed mice ( $20 \mu \mathrm{l}$ serum in $450 \mu \mathrm{l}$ of serum-free media). Samples were incubated at $37^{\circ} \mathrm{C}$ for $4 \mathrm{~h}$. RNA was extracted from the cells using a commercial kit (RNeasy, Qiagen, Germantown, Maryland) according to the manufacturer's instructions. This RNA was then aliquoted and frozen at $-80^{\circ} \mathrm{C}$.

\section{MicroRNA sequencing}

Total RNA, including small RNAs, was extracted using a commercial extraction kit from Total RNA Purification Kit from Norgen Biotek Corp (Thorold, ON, Canada) in cultured mCECs in the SCIP assay. RNA quality and quantity were analyzed using a Bioanalyzer 2100 (Agilent, CA, USA) to ensure a RIN number > 7.0. A small RNA library was prepared using TruSeq Small RNA Sample Prep Kit (Illumina, San Diego, USA) using 1 (g of total RNA. Fifty bp single-end sequencing on an Illumina HiSeq 2500 at LC Sciences (Hangzhou, China) was performed as per the manufacturer's instructions.

\section{Bioinformatics analysis}

Adapter dimers, junk, low complexity, common RNA families including rRNA, tRNA, snRNA and snoRNA and repeats were subjected to an in-house program, ACGT101-miR (LC Sciences, Houston, Texas, USA). Unique sequences 18-26 nucleotides in length were mapped to specific species precursors in miRbase 22.0 by BLAST search to identify known miRNAs and novel
$3 p-$ and $5 p$-derived miRNAs. The remaining sequences were mapped to selected species precursors (with the exclusion of specific species) in miRbase 22.0 via BLAST search. The mapped pre-miRNAs were then BLASTed against the specific species genomes to establish their genome locations. These were defined as known miRNAs. Secondary structure predictions were established by: 1$)$ number of nucleotides in one bulge in stem $(\leq 12)$, 2) number of base pairs in the stem region of the predicted hairpin $(\geq 16), 3)$ cutoff of free energy $(\mathrm{kCal} / \mathrm{mol} \leq$ $-15), 4$ ) length of hairpin (up and down stems + terminal loop $\geq 50), 5$ ) length of hairpin loop $(\leq 20), 6)$ number of nucleotides in one bulge in mature region $((\leq 8)$, 7) number of biased errors in one bulge in mature region $(\leq 4), 8)$ number of biased bulges in mature region $(\leq 2), 9)$ number of errors in mature region $(\leq 7), 10)$ number of base pairs in the mature region of the predicted hairpin $(\geq 12)$, and 11$)$ percent of mature regions in stem $(\geq 80)$. In total, 11 samples were analyzed with 6 biological replicates in the FA group and 5 biological replicates in the CAPs group.

\section{Target prediction of differentially expressed microRNAs}

Predicted genes targeted by the most abundant miRNAs were assessed using two algorithms, TargetScan (http:// www.targetscan.org/) and Miranda 3.3a (http://www. microrna.org/), to assess binding sites. Data predicted by these algorithms were combined and subsequent overlaps were calculated. The GO terms and KEGG pathways of abundant miRNAs and targets were also annotated. Significant GO terms were calculated using the following Hypergeometric equation described below:

$$
P=1-\sum_{i=0}^{s-1} \frac{\left(\frac{B}{i}\right)\left(\frac{T B-B}{T S-i}\right)}{\left(\frac{T B}{T S}\right)}
$$

Differential expression with 3 randomly selected miRNAs in the $p<0.01$ group were validated using qPCR (data not shown).

\section{Circulating serum-borne microRNAs}

Fireplex multiplexing technology (Abcam, Cambridge, MA) was used to quantify the most significantly altered $(p<0.01)$ serum miRNAs of murine origin identified following the miRNA sequencing experiment mentioned above. Briefly, samples were assayed in duplicates and 20 ( $\mathrm{L}$ of serum per replicate was hybridized to the Fireplex plate and captured by target-specific probes embedded in Firefly barcoded hydrogel particles for $60 \mathrm{~min}$ at room temperature. Oligonucleotide adapters were then ligated to each end of the hybridized miRNA as PCR priming sites and amplified for $60 \mathrm{~min}$. Labeled miRNAs were 
then dehybridized from particles and underwent onestep RT-PCR with a biotinylated primer. PCR products were then rehybridized to the original Firefly particles and subsequently incubated with a fluorescent reporter for detection. Particles were then scanned using an EMD Millipore 8HT flow cytometer (Burlington, MA, USA). MiRNAs used for normalization included mmu-mir425-5p_r-1, mmu-mir-744-5p_r-1, mmu-mir-16-5p. Celmir-70-3p was used as an exogenous control. Flow cytometry files were analyzed using Firefly Analysis Workbench (Abcam, Cambridge, MA).

\section{mRNA prediction and network analysis}

The Bioconductor package miRNAtap was used to predict mRNA targets. Targets were aggregated from 5 prediction algorithms: DIANA [47], Miranda [48], PicTar [49], TargetScan [50], and miRDB [51]. mRNA targets found in at least 2 algorithms were considered valid. Then, a ReactomePA [52] package was used to analyze reactome pathway enrichment on predicted mRNA targets. The $\mathrm{R}$ script performing all analyses and a list of predicted mRNA targets are available at: https:/github. com/Perl-R/190606-Uranium-miRNA.

\section{mmu-let-7a transfections}

Mmu-let-7a mimic and let-7a negative control miRNA (Qiagen, Germantown, MD) were transfected into a monolayer of mCECs using the Applied Biosystems Electric Cell-substrate Impedance Sensing (ECIS) system at $10^{5}$ cells per well. Reverse transfection protocol was utilized as per the HiPerfect Transfections manufacturer's instructions (Qiagen). After cells were grown to confluence, as determined by a plateau in transendothelial electrical resistance (TEER), serum was added from FA- and CAPs-exposed mice and grown for $45 \mathrm{~h}$. TEER readings were captured in real-time every $10 \mathrm{~min}$ until the final endpoint.

\section{Statistics}

MiRNA differential expression was based on normalized deep-sequencing counts and analyzed by selectively using Fisher's exact test, Chi-squared nXn test, Student's $t$-test or ANOVA, based on experimental design. The data heatmap where the individual $\mathrm{z}$ values (repeated) or $\log _{10}$ (non-repeated) within a matrix are represented within the red-blue color scheme, as indicated in the heat-map. For the transfection studies, a one-way ANOVA followed by Tukey's multiple comparisons, post-hoc test was performed.

\section{Results}

Particulate matter (PM) and wind characterization

Concentrated particulate levels varied substantially from day-to-day during the 2 -week period (Fig. 1a). The $4 \mathrm{~h}$ exposure in the mobile laboratory, however, showed a relatively consistent operation (Fig. 1b). Relative to the AirCARE1 location, the wind gusts most often blew from the southwest or northeast and varied throughout the exposure period (Fig. 1c). The average exposure for all $4 \mathrm{~h}$ periods was $96.6 \pm 60.4 \mu \mathrm{g} / \mathrm{m}^{3}$. The average concentrations of key metals are shown in Fig. 1d. Metals detected in the filter samples included Mo, Cd, Gd, W, $\mathrm{Pb}, \mathrm{U}, \mathrm{Mg}, \mathrm{Al}, \mathrm{V}, \mathrm{Fe}, \mathrm{Ni}, \mathrm{Cu}, \mathrm{Zn}, \mathrm{As}$, and Se. While samples previously collected from the Claim 28 mine-site, showed the presence of both $\mathrm{U}$ and $\mathrm{V}$ (highlighted in the figure, Zychowski et al. 2018), our current results suggest that metals present in airborne CAPs included higher levels of $\mathrm{Al}$ and $\mathrm{Fe}$.

\section{Bronchoalveolar lavage and number of cells}

Cellularity was significantly altered between FA and CAPs exposure. Macrophage counts and neutrophils were significantly increased in the CAPs exposed group compared to FA (Fig. 2a, b). However, protein (mg/mL), a marker of pulmonary endothelial barrier integrity, was not significantly different between exposure groups (Fig. 2c).

\section{MicroRNA differential expression}

There were 27 highly significant $(p<0.01)$ differentially expressed miRNAs of murine origin between FA- and CAPs-exposed groups (Fig. 3a, b) in mCECs, as measured in the SCIP assay. From the total miRNAs detected, 2 were upregulated and 25 were downregulated in the $p<0.01$ group, 32 were upregulated and 90 were downregulated in the $p<0.05$ group (122 total differentially expressed), and 41 were upregulated and 124 were downregulated in the $p<0.1$ group (165 total differentially expressed) (Fig. 3c). Of the 269 detected miRNAs, 184 were similar between FA and CAPs exposed groups (Fig. 3d). Two of the most highly expressed miRNAs in the CAPs exposed groups were in the mmu-let-7a family, which warranted further in vitro transfection experiments.

\section{Gene ontology}

Gene ontology (GO) represents the initiative of gene and gene products. Significant GO terms are listed in Supplemental Table 1. The highest significant percentage of genes involve biological processes, membranes and molecular functions (Fig. 4). The scatterplot of GO Enrichment (Fig. 5a) graphically depicts the rich factor. Rich factor $=($ number of target genes in the GO)/total number of genes in GO term). The larger the rich factor is the greater the enrichment. 

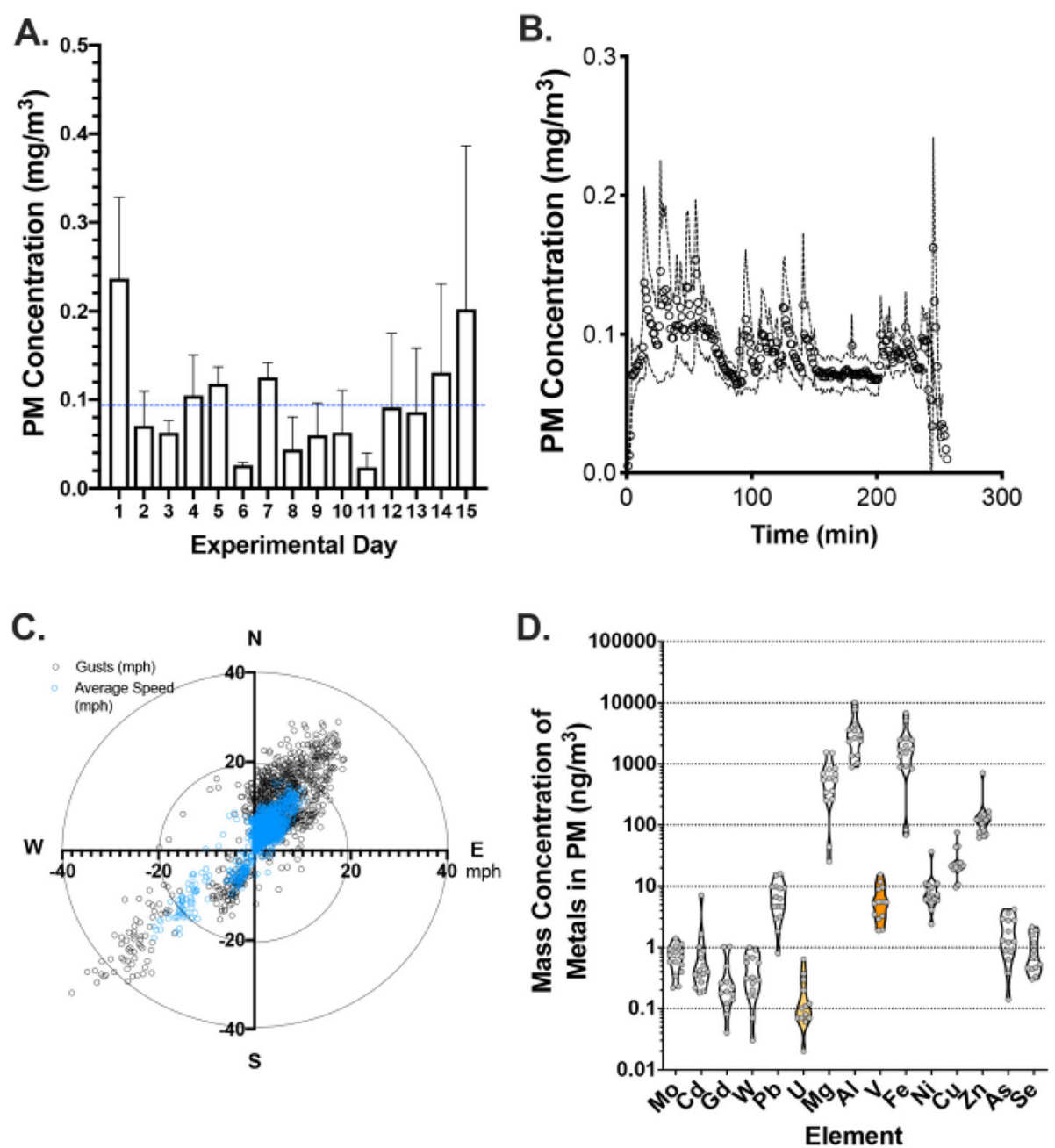

Fig. 1 Exposures in Blue Gap Tachee, AZ. CAPs characterization data via analytical methods and AirCARE 1 wind exposure metrics. a CAPs concentration on each exposure day $\left(\mathrm{mg} / \mathrm{m}^{3}\right) \mathbf{b}$ CAPs concentration $\left(\mathrm{mg} / \mathrm{m}^{3}\right)$ over the exposure time frame. The average CAPs concentration over $4 \mathrm{~h}$ was recorded at $96.6 \pm 60.4 \mathrm{\mu g} / \mathrm{m}^{3}$ (mean \pm SEM) c Wind speed as assessed at the exposure site. Wind generally blew from the southwest or northeast throughout the exposure period. $\mathbf{d}$ Mass concentration of metals in CAPs $\left(\mathrm{mg} / \mathrm{m}^{3}\right)$

\section{KEGG analysis}

KEGG analysis revealed significant changes between FA and CAPs groups as measured in the SCIP assay (Fig. 5b). A complete list of significantly altered pathways is listed in Supplemental Table 2. The most significantly changed groups involved pathways in cancer, axon guidance and Wnt signaling. Pathways involving adherens junctions, and focal adhesion were also among the most highly altered pathways.

\section{Serum-borne microRNAs and associations with microRNAs in the endothelium}

From the 27 murine-origin miRNAs that were analyzed in the serum, 9 were differently expressed $(p<0.05)$. All serum-borne miRNAs, except for one (mmu-mir-425p $\mathrm{r}-1)(8 / 9$ miRNAs), demonstrated the same change in expression, either upregulation or downregulation as seen in mCEC miRNAs following SCIP (Fig. 6a-i). Linear regression analysis between the serum-borne miRNAs and mCEC miRNAs as measured in the SCIP assay indicated linear associations among several of the miRNAs, including significant $(p<0.05)$ associations in mmu-mir143-3p_4-1 $\left(R^{2}=0.4671, p=0.0204\right)$, mmu-mir-28a-3p $\left(R^{2}=0.7136, \quad p=0.0011\right)$ and mmu-mir-322-3p_r +1 $\left(R^{2}=0.5438, p=0.0096\right)$ (Fig. 7b, d, and e, respectively).

\section{Target mRNA pathway analysis}

Pathway analysis revealed the most significantly upregulated miRNAs $(p<0.01)$ targeted MAP kinase activation, axon guidance, and collagen-related genes (Fig. 8a). The most significantly downregulated genes $(p<0.01)$ affected mRNA targets involving RAF/MAP kinases, signaling by tyrosine kinases, NTRK (neurotrophin receptors), axon 

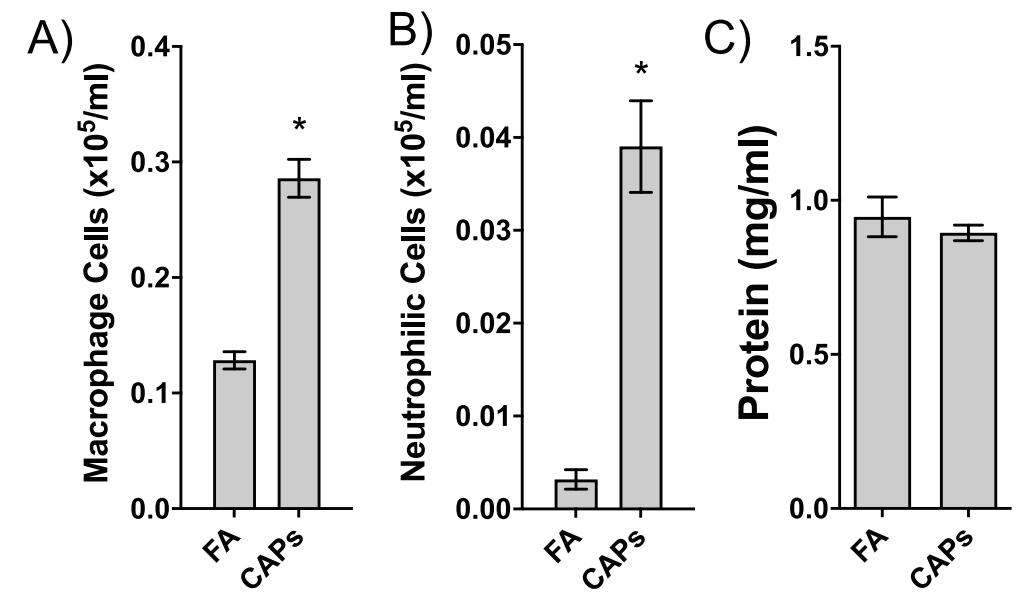

Fig. 2 Bronchoalveolar lavage (BAL) fluid parameters. Following euthanasia of each mouse, BAL was collected via tracheal puncture and assessed for number of inflammatory cells for a macrophages (cells $\times 10^{5} / \mathrm{mL}$ ) and $\mathbf{b}$ neutrophils (cells $\times 10^{5} / \mathrm{mL}$ ) $\mathbf{c}$ protein $(\mathrm{mg} / \mathrm{mL}$ ). Macrophage and neutrophilic cell counts were significantly upregulated in the CAPs exposure group relative to FA exposure, based on a Student's t-test ( $p<0.05$ ), indicating an inflammatory pulmonary response following CAPs exposure

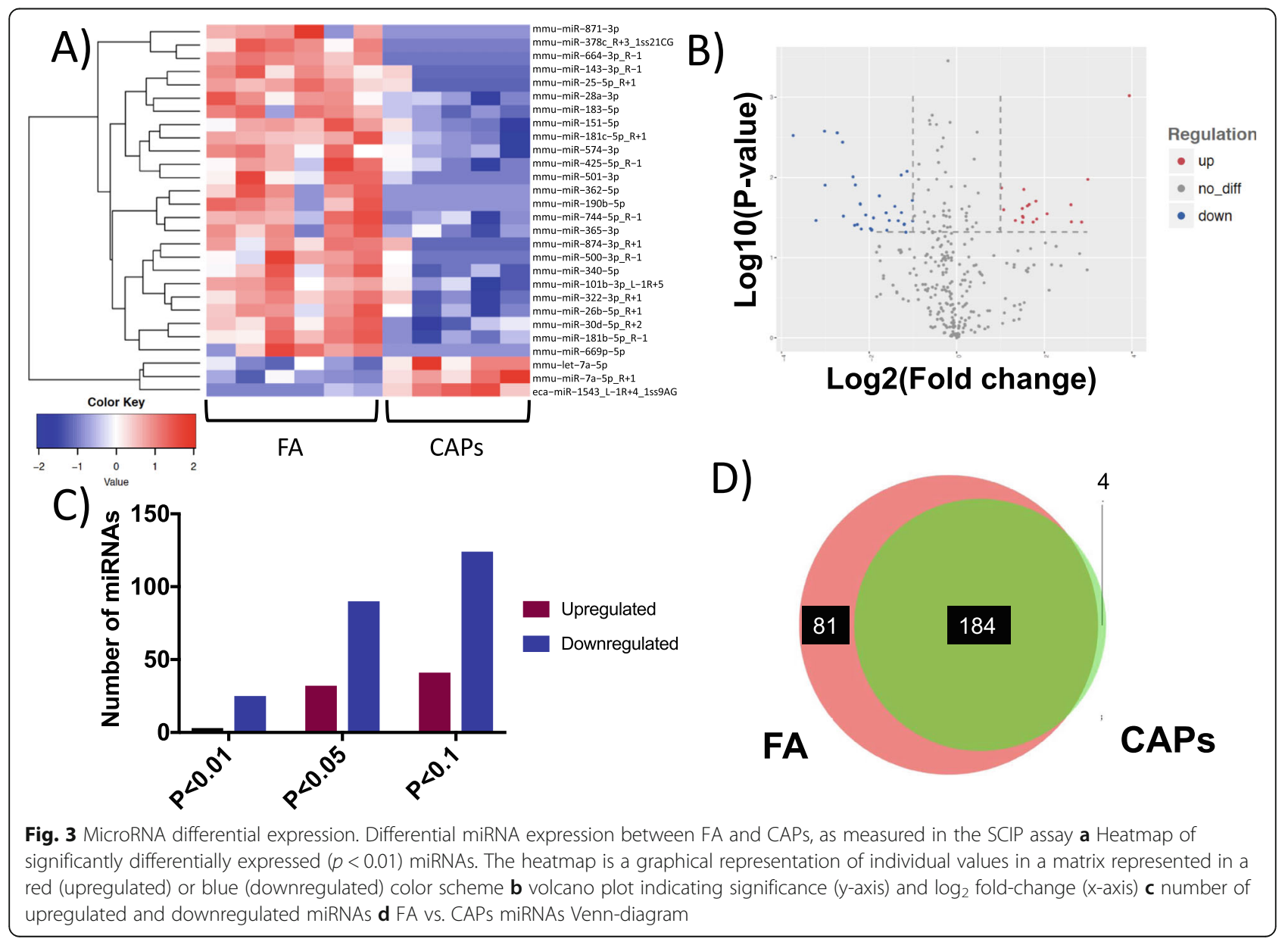




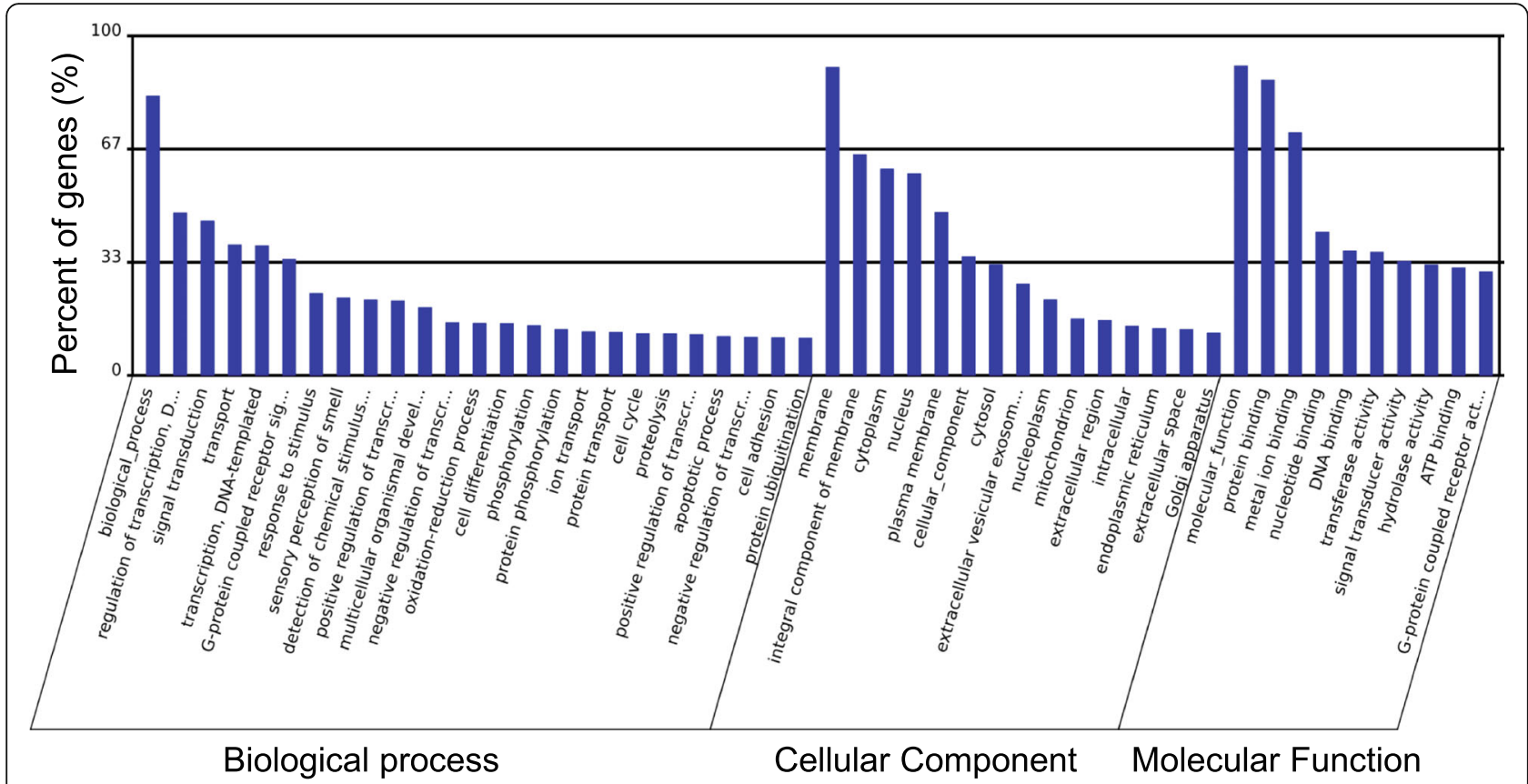

Fig. 4 Gene ontology. Representation of gene and gene product attributes via gene ontology (GO, http://www.geneontology.org). Percent genes (\%) involved in biological processes, cellular component or molecular function. Significant GO terms were calculated and those GO terms with a $p$-value $<0.05$ are defined as significant

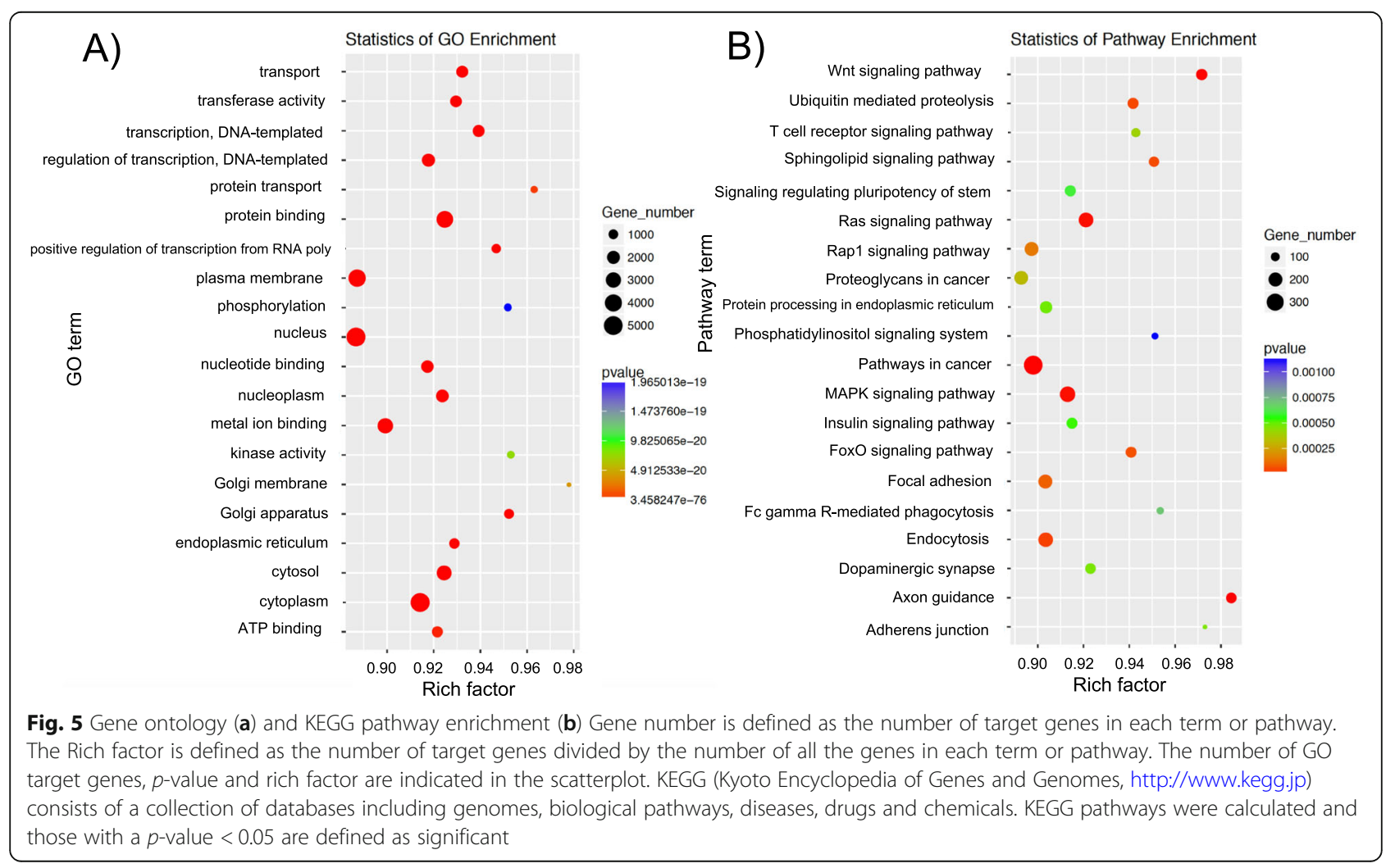




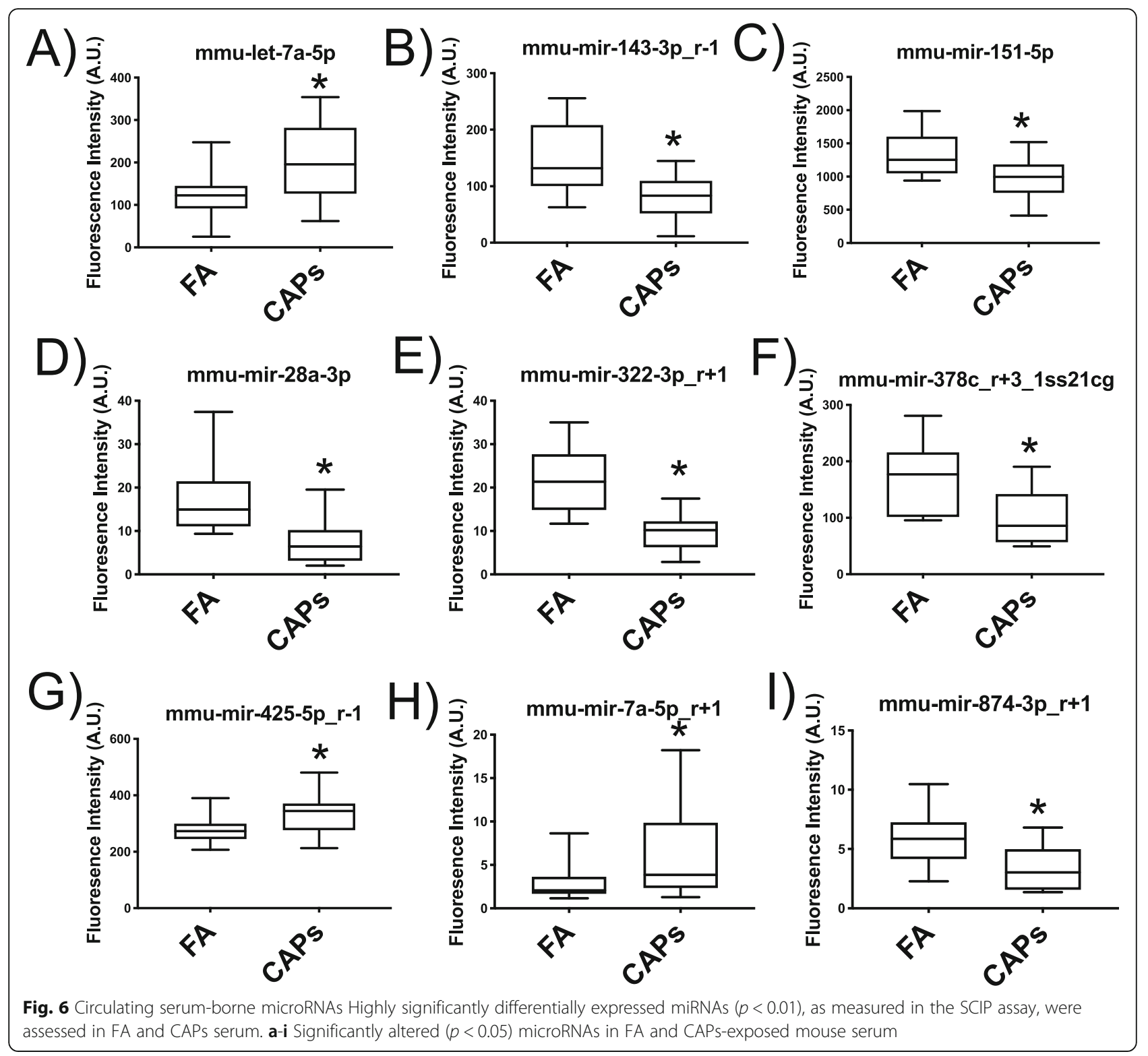

guidance and CRMPs (collapsin response mediator protein) in Sema3A signaling (Fig. 8b).

\section{Let-7a overexpression in mCECs}

Mmu-let-7a was significantly upregulated in the CAPsexposed group, as measured in the SCIP assay (Fig. 3a), which warranted further investigation into this miRNA's role in the cerebrovascular endothelial cells. Results suggest that overexpression of transfected exogenous mmulet-7a in the presence of serum from CAPs-exposed mice resulted in a significant decrease in $\mathrm{MCEC}$ barrier integrity, as determined by transendothelial electrical resistance (TEER, ^, Fig. 9a). Let-7a mimic/CAPs group demonstrated a significant TEER decrease from both the FA/let-7a control and CAPs/let-7a control (Fig. 9b).
Results suggest that overexpression of mmu-let-7a may decrease mCEC integrity in vitro.

\section{Discussion}

This is the first assessment of mCEC miRNA alterations as a result of serum-borne factors from mice exposed to FA and CAPs. Using a real-time, inhalation toxicology system, we captured concentrated ambient, on-site CAPs near the Claim 28 AUM on Navajo Nation, AZ for inhalation exposure. Because of the uniqueness of our paradigm we have preliminarily assessed neurovascular toxicity, using a novel in vitro assay, as a result of these inhaled exposures.

Due to this improper clean-up, many of the surrounding tribal communities are exposed to varying degrees of 


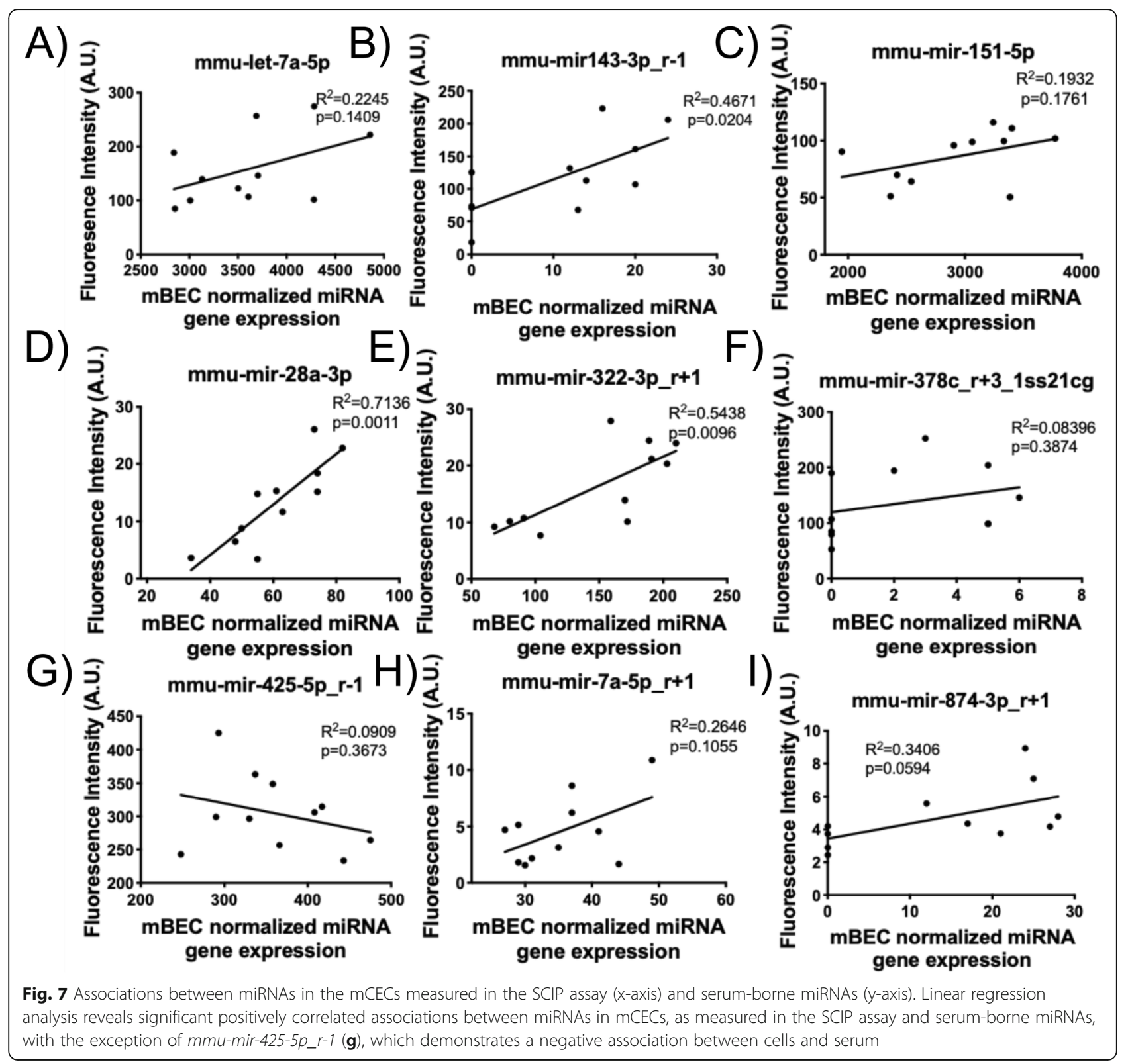

contaminant metal mixtures, including uranium (U), arsenic (As) and vanadium (V) [4-6]. Metals-based exposure has been implicated in several adverse health effects, including pulmonary and cardiovascular diseases, neurological disorders and cancer [53-56]. Recent epidemiological evidence from the area has suggested cognitive deficits in Navajo children compared to the national average [57]. We surmise that inhaled exposures from AUMs may play a role in this etiology of neurological outcomes.

We assessed the most significantly differentially expressed miRNAs $(p<0.01)$ between CAPs and FAexposed mice, as measured in the SCIP assay. In the CAPs exposure group, the most highly upregulated
miRNAs of murine origin were in the let-7a family (mmu-let-7a-5p, mmu-miR-7a-5p_R +1 ). These data are consistent with epidemiological evidence demonstrating upregulated let-7a in the serum of elderly men exposed to CAPs at the 1-year window [58]. Additionally, acrolein-exposed human umbilical vein endothelial cells exhibited a decrease in endothelial cell migration and insulin sensitivity following induction of let-7a [59]. Let-7a plays a prominent role in cell growth and differentiation [60], which may contribute to cerebrovascular endothelial function. In addition, overexpression of let-7a regulates angiogenesis by targeting TGFBR3 and reduces endothelial cell migration rate, in vitro [61]. Other studies from our laboratory have noted BBB leakage 


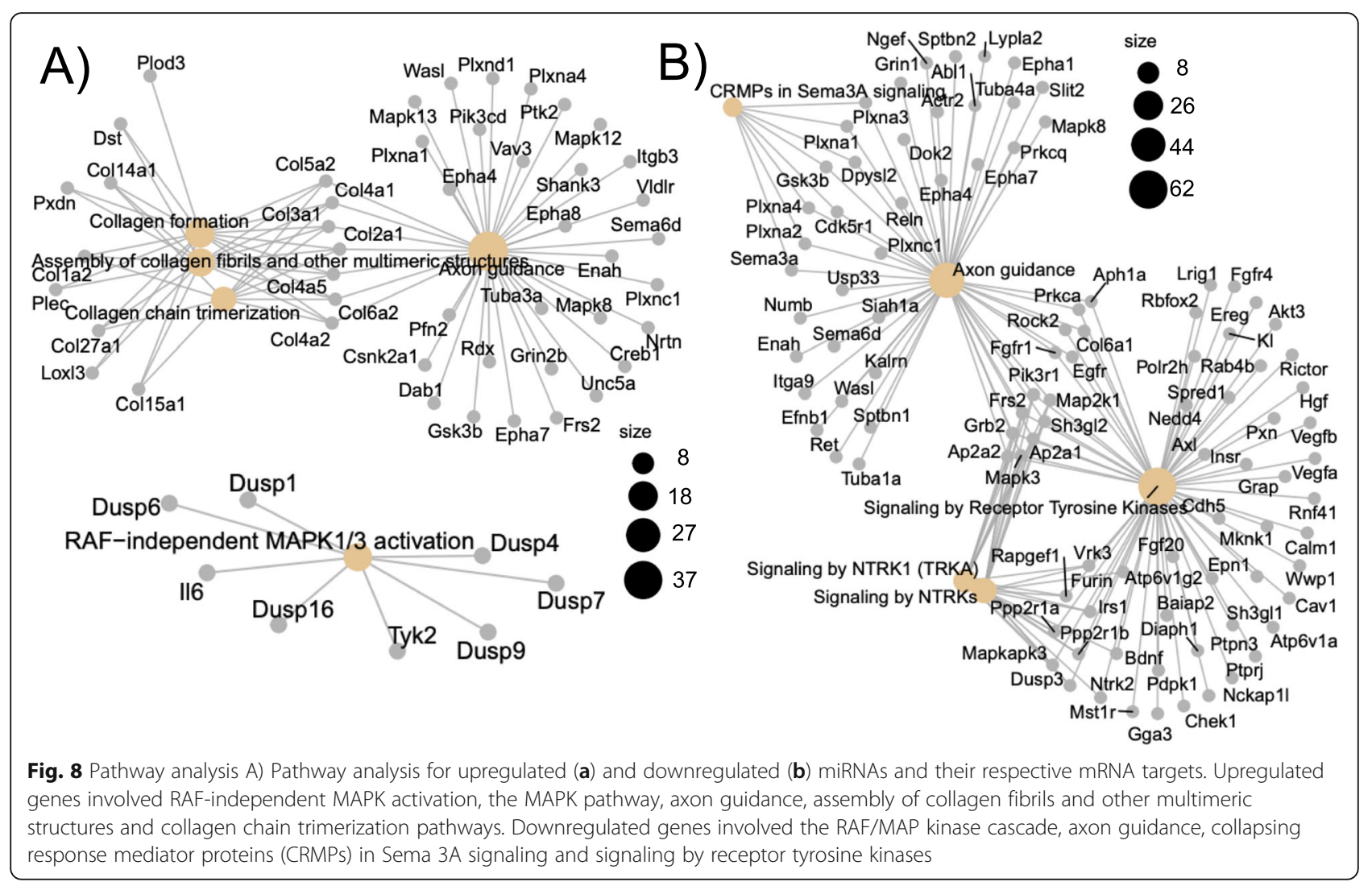

following other inhaled exposures such as multi-walled carbon nanotubes [34, 62] and ozone, a common ground-level air pollutant [35]. Similarly, we found that let-7a overexpression using a transfected let-7a mimic resulted in a decrease of transendothelial barrier resistance as measured in the SCIP assay. However, our current data suggest that upregulation of miRNA may play a unique role in endothelial or BBB disruption following inhaled air pollution exposures. In support of our findings are documented associations between metal exposure and circulating miRNAs [29-31]. Air pollution is a mixture of particulates and gases such as $\mathrm{O}_{3}$ and $\mathrm{NO}_{2}$
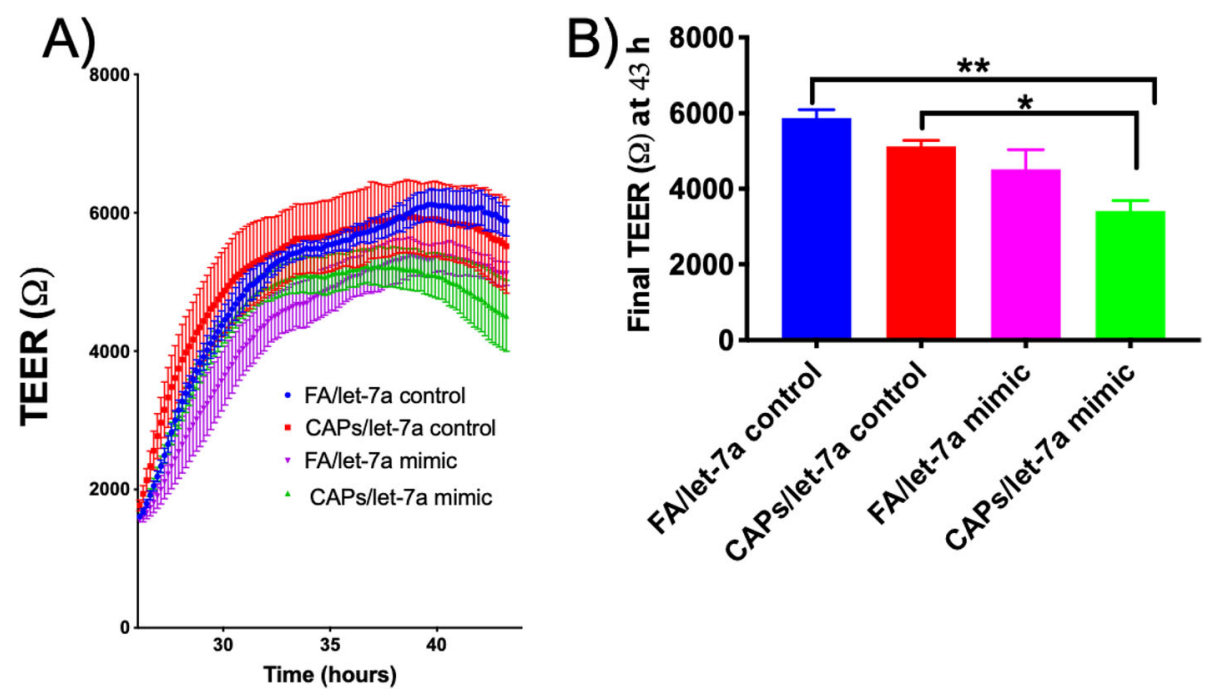

Fig. 9 Transendothelial electrical resistance (TEER) mCEC resistance following transfections with mmu-let-7a controls and mimics and incubation with serum from FA and CAPs-exposed mice. ANOVA followed by Tukey's post-hoc test indicates significant differences between groups ( $p<$ 0.05). a mCEC transendothelial resistence over time. $\mathbf{b}$ final transendothelial resistence at $43 \mathrm{~h}$ after curve plateau 
and human populations exposed to traffic pollution exhibit alterations in circulating miRNAs following a minimal $2 \mathrm{~h}$ exposure [63]. Circulating miRNAs are also biomarkers of radiation-induced cardiac toxicity [64], and low dose occupational exposure to organic solvents was associated with upregulated miRNAs, including miR_6819_5p and miR_6778_5p [65]. Additionally, bioinformatic analysis suggests that circulating miRNAs reflect the adverse toxic consequences in the lung, heart, kidney and brain [32, 33].

One of the most profound insights from this study is the similarity between $89 \%(8 / 9)$ of the miRNAs tested in cells, as measured by the SCIP assay and serum. These miRNAs assessed in the FA or CAPs serum exhibited the same directional change (either upregulation or downregulation) as the cellular miRNAs, as measured in the SCIP assay. This may suggest that certain miRNAs could potentially transfer from the extracellular compartment into the endothelium. In addition to miRNA translocation, other mechanisms may be at play such as extracellular matrices or serum-borne peptide fragments influencing miRNA transcriptional change within the endothelium. Additionally, these key cellular and serum-borne miRNAs, may suggest potential therapeutic targets in populations exposed to high levels of air pollution. Previous literature has suggested that, following inhaled toxicant exposure, peptide fragments are derived from lung circulate and interact with endothelial scavenger receptors, thereby activating downstream targets in the inflammasome including NFkB [17, 34, 62]. Many of the downstream target genes, as determined by pathway analysis, such as ROCK2 and VEGFA and B are involved in actin-cytoskeleton reorganization and/or angiogenesis. This may indicate that these altered miRNAs are thereby responsible for regulating endothelial BBB disruption following inhaled toxicant exposure as previously documented from our laboratory [34, 35]. In support of our findings, previous reports have implicated air pollution in neuroinflammation and diseases of the central nervous system [39-41]. Subchronic exposure to diesel exhaust was shown to elevate markers of early neuropathology such as tau and $A \circledast 42$, two markers of Alzheimer's disease and Synuclein, a preclinical biomarker of Parkinson's disease-like pathology [39]. Additionally, PM has been identified in olfactory bulb neurons following long-term air pollution exposures [66]. Previous studies from our laboratory indicated that Fasudil, a wellestablished ROCK inhibitor, prevents particulate-induced BBB dysfunction [34]. Our data now suggest that these downregulated miRNAs can control ROCK expression and may eventually serve as potential therapeutic targets in vulnerable, CAPs-exposed populations.

By utilizing the AirCARE1 inhalation system, we anticipate a realistic characterization of the overall contribution of on-site, wind-blown dusts to health outcomes. Although this mobile laboratory is able to capture real-time, in situ CAPs, one limitation of the AirCARE1 exposure paradigm was that no head-to-head comparisons with other regional PM were made, which is a current limitation of this work. In the present study, the concentration levels in the chamber mimicked concentrations found in industrial cities around the world $[67,68]$. However, they were still far below concentrations found in dust storms in desert environments [69]. Analytical methods revealed CAPs metal-enrichment including detectable levels of Mo, $\mathrm{Cd}, \mathrm{Gd}, \mathrm{W}, \mathrm{Pb}, \mathrm{U}, \mathrm{Mg}, \mathrm{Al}, \mathrm{V}, \mathrm{Fe}, \mathrm{Ni}, \mathrm{Cu}, \mathrm{Zn}, \mathrm{As}$ and $\mathrm{Se}$. While many of these metals have been well-established as drivers of cardiopulmonary toxicity $[6,70,71]$, others, including rare earth metals such as Gd have been less characterized as contributors to health effects. Future studies will focus on PM organic composition in the chamber in addition to the inorganic, metals fraction.

One limitation of this study is the in vitro nature of our bioassay and future studies may focus on isolation of brain endothelial cells post-exposure. Another key limitation of the study was the limited time frame for collection/analysis of CAPs relative to wind direction. While we had a reasonable distribution of wind coming from the mine site, we did not note any obvious impact of wind directionality on the levels of uranium or vanadium. Due to technical limitations with the chamber filters, we were also unable to analyze the CAPs organic fraction. Longer exposure campaigns would help to better understand the connection between meteorological factors and resuspension of mine site-derived metal contaminants.

\section{Conclusions}

In the present study, we show that serum from mice exposed to ambient AUM-derived CAPs in the central region of Navajo Nation (Claim 28) induces significant changes in cellular murine miRNA expression as measured in the SCIP assay. Validation of the highly differentially expressed cellular miRNAs in the serum revealed that $30 \%$ were significantly altered. Furthermore, $89 \%$ of the miRNAs assessed in the serum of FA or CAPs-animals exhibited the same directional change (either upregulation or downregulation) as the cellular miRNAs. These data suggest that miRNAs from systemic circulation may translocate to the endothelium following CAPs exposure. The relative characterization of circulating serum-borne miRNAs and cellular miRNA expression following SCIP may add insight into the most significant potential clinical targets. More importantly, because the AirCARE1 CAPs exposure paradigm captures real-time, on-site world air pollution, these data are also directly impactful and translationally relevant to the Native American communities at risk for mine-site 
dust exposure. To our knowledge, this is the first study of its kind to suggest that environmentally-driven changes to the circulating/extracellular milieu may be responsible for driving intracellular endothelial miRNA alterations, which may include both upregulated and downregulated miRNAs. Understanding the complex protein/lipid/small molecule changes to the circulation after air pollution exposures will be crucial to understanding the endothelial responses, especially in the context of vascular disease. Further mechanistic research highlighting miRNA trafficking and potential mechanistic miRNA targets is warranted. Future studies should focus on the role of circulating extracellular ligands as drivers of cellular miRNA expression.

\section{Supplementary information}

Supplementary information accompanies this paper at https://doi.org/10. 1186/s12989-020-00361-3.

\section{Additional file 1.}

Additional file 2.

\section{Acknowledgments}

We would like to thank Dr. Jesse Denson for manuscript editing and preparation. We also would like to thank Ryan Crane, BS, and Zachary Klaver, MSE, of the Michigan State University Exposure Science Laboratory for their efforts on sample preparation and trace metals analysis.

\section{Authors' contributions}

Bethany Sanchez was responsible for executing AirCARE1 exposures, study design and manuscript writing. Xixi Zhou undertook the bioinformatics pathway analysis for the miRNA sequencing experiments. Amy S. Gardiner assisted with transfection experiments. Masako Morishita undertook the CAPs chemical analysis. Ryan Lewandowski, James Wagner and Jack Harkema assisted with AirCARE1 exposures and study design. Katherine Zychowski and Matthew Campen were responsible for overseeing the entire study, experimental design, manuscript writing and execution of miRNA sequencing experiments. The authors read and approved the final manuscript.

\section{Funding}

This work has been supported by NIEHS (K99 ES029104, R00 ES029104, R01 ES026673) and the University of New Mexico Metal Exposure and Toxicity Assessment on Tribal Lands in the Southwest (UNM METALS) Superfund Research Program (P42 ES025589).

\section{Availability of data and materials}

All data are available upon reasonable request. Bioinformatics and sequencing data are made available through a repository found at https:// github.com/Perl-R/190606-Uranium-miRNA.

\section{Ethics approval and consent to participate}

Studies were conducted with full approval by the Institutional Animal Care and Use Committees of the University of New Mexico and Michigan State University.

\section{Consent for publication}

All authors consent to publication of this manuscript.

\section{Competing interests}

The authors declare no competing interests.

\section{Author details}

'Department of Pharmaceutical Sciences, University of New Mexico-Health Sciences Center, Albuquerque, NM 87131, USA. ${ }^{2}$ Department of Cell Biology and Physiology, University of New Mexico-Health Sciences Center, Albuquerque, NM 87131, USA. ${ }^{3}$ Department of Family Medicine, College of Human Medicine, Michigan State University, East Lansing, MI, USA. ${ }^{4}$ Department of Pathobiology and Diagnostic Investigation, College of Veterinary Medicine, Michigan State University, East Lansing, MI, USA. ${ }^{5}$ Southwest Research and Information Center, Albuquerque, NM, USA. ${ }^{6}$ College of Nursing, MSC09 53601 University of New Mexico-Health Sciences Center, Albuquerque, NM 87131, USA.

Received: 14 October 2019 Accepted: 22 June 2020

Published online: 01 July 2020

\section{References}

1. Johnston BR, Dawson S, Madsen G. Uranium mining and milling: Navajo experiences in the American Southwest. In: Indians and energy in the Southwest: exploitation or opportunity; 2010.

2. Brugge D, Benally T, Yazzie-Lewis E. The Navajo people and uranium mining. Albuquerque: UNM Press; 2007.

3. Voyles TB. Wastelanding: legacies of uranium mining in Navajo country. Minneapolis: U of Minnesota Press; 2015.

4. Hoover J, et al. Elevated arsenic and uranium concentrations in unregulated water sources on the Navajo Nation, USA. Expo Health. 2017:9(2):113-24.

5. Lewis J, Hoover J, MacKenzie D. Mining and environmental health disparities in native American communities. Curr Environ Health Rep. 2017: 4(2):130-41

6. Zychowski KE, et al. Respirable Uranyl-vanadate-containing particulate matter derived from a legacy uranium mine site exhibits potentiated cardiopulmonary toxicity. Toxicol Sci. 2018;164(1):101-14.

7. Powers $\mathrm{M}$, et al. Low-to-moderate arsenic exposure and respiratory health in American Indian communities. Ann Am Thorac Soc. 2018; 15(Supplement_2):S128-9.

8. Rahman A, Hashem A, Nur ATS. Potable water quality monitoring of primary schools in Magura district, Bangladesh: children's health risk assessment. Environ Monit Assess. 2016;188(12):680.

9. Sanchez TR, et al. Urinary metals and metal mixtures in Bangladesh: exploring environmental sources in the health effects of arsenic longitudinal study (HEALS). Environ Int. 2018;121(Pt 1):852-60.

10. Wasserman GA, et al. A cross-sectional study of water arsenic exposure and intellectual function in adolescence in Araihazar, Bangladesh. Environ Int. 2018;118:304-13.

11. Harmon ME, et al. Residential proximity to abandoned uranium mines and serum inflammatory potential in chronically exposed Navajo communities. J Expo Sci Environ Epidemiol. 2017;27(4):365-71.

12. Liu C, et al. The acute effects of fine particulate matter constituents on blood inflammation and coagulation. Environ Sci Technol. 2017;51(14):8128-37.

13. Shakya KM, et al. Roadside exposure and inflammation biomarkers among a cohort of traffic police in Kathmandu, Nepal. Int J Environ Res Public Health. 2019;16(3):377.

14. McCarthy JF, Shugart LR. Biomarkers of environmental contamination; 1990.

15. Cung $\mathrm{H}$, et al. Characterization of a novel endothelial biosensor assay reveals increased cumulative serum inflammatory potential in stabilized coronary artery disease patients. J Transl Med. 2015;13:99.

16. Paffett $\mathrm{ML}$, et al. Ozone inhalation impairs coronary artery dilation via intracellular oxidative stress: evidence for serum-borne factors as drivers of systemic toxicity. Toxicol Sci. 2015;146(2):244-53.

17. Robertson $\mathrm{S}$, et al. CD36 mediates endothelial dysfunction downstream of circulating factors induced by 03 exposure. Toxicol Sci. 2013;2:304-11.

18. Zychowski KE, et al. Serum from obstructive sleep apnea patients induces inflammatory responses in coronary artery endothelial cells. Atherosclerosis. 2016:254:59-66.

19. Channell MM, et al. Circulating factors induce coronary endothelial cell activation following exposure to inhaled diesel exhaust and nitrogen dioxide in humans: evidence from a novel translational in vitro model. Toxicol Sci. 2012;127(1):179-86.

20. Schisler JC, et al. Endothelial inflammatory transcriptional responses to an altered plasma exposome following inhalation of diesel emissions. Inhal Toxicol. 2015;27(5):272-80.

21. Ruiz-Vera T, et al. Circulating miRNA-126, -145 and -155 levels in Mexican women exposed to inorganic arsenic via drinking water. Environ Toxicol Pharmacol. 2019;67:79-86. 
22. Bardin JM, et al. Anti-LAV/HTLV III antibodies in wives of seropositive hemophilic patients. Presse Med. 1986;15(33):1686-7.

23. Miller PR, et al. Extraction and biomolecular analysis of dermal interstitial fluid collected with hollow microneedles. Commun Biol. 2018;1:173.

24. Tran BQ, et al. Proteomic characterization of dermal interstitial fluid extracted using a novel microneedle-assisted technique. J Proteome Res. 2018;17(1):479-85

25. Khalid $U$, et al. A urinary microRNA panel that is an early predictive biomarker of delayed graft function following kidney transplantation. Sci Rep. 2019;9(1):3584.

26. Lin $X$, et al. Urinary miRNA-29a-3p levels are associated with metabolic parameters via regulation of IGF1 in patients with metabolic syndrome. Biomed Rep. 2019;10(4):250-8.

27. Wang $C$, et al. Droplet digital PCR improves urinary exosomal miRNA detection compared to real-time PCR. Clin Biochem. 2019:67:54-9.

28. Bretzke G, Rosner K. Hemobilia. Z Arztl Fortbild (Jena). 1978;72(5):209-10.

29. Chen W, et al. Multiple metals exposure and chromosome damage: exploring the mediation effects of microRNAs and their potentials in lung carcinogenesis. Environ Int. 2019;122:291-300.

30. Deng Q, et al. Co-exposure to metals and polycyclic aromatic hydrocarbons, microRNA expression, and early health damage in coke oven workers. Environ Int. 2019;122:369-80.

31. Ge QD, et al. MiR-132, miR-204 and BDNF-TrkB signaling pathway may be involved in spatial learning and memory impairment of the offspring rats caused by fluorine and aluminum exposure during the embryonic stage and into adulthood. Environ Toxicol Pharmacol. 2018;63:60-8.

32. Donovan PJ, et al. Studies on the migration of mouse germ cells. J Cell Sci Suppl. 1987:8:359-67.

33. Thounaojam MC, Kaushik DK, Basu A. MicroRNAs in the brain: it's regulatory role in neuroinflammation. Mol Neurobiol. 2013;47(3):1034-44.

34. Aragon MJ, et al. Serum-borne bioactivity caused by pulmonary multiwalled carbon nanotubes induces neuroinflammation via blood-brain barrier impairment. Proc Natl Acad Sci U S A. 2017;114(10):E1968-76.

35. Tyler $C R$, et al. Aging exacerbates neuroinflammatory outcomes induced by acute ozone exposure. Toxicol Sci. 2018;163(1):123-39.

36. Tyler $C R$, et al. Surface area-dependence of gas-particle interactions influences pulmonary and neuroinflammatory outcomes. Part Fibre Toxicol. 2016;13(1):64

37. Penn $\mathrm{DL}$, et al. Pathological mechanisms underlying aneurysmal subarachnoid haemorrhage and vasospasm. J Clin Neurosci. 2015;22(1):1-5.

38. Wellenius GA, Schwartz J, Mittleman MA. Air pollution and hospital admissions for ischemic and hemorrhagic stroke among medicare beneficiaries. Stroke. 2005:36(12):2549-53.

39. Levesque $S$, et al. Air pollution \& the brain: subchronic diesel exhaust exposure causes neuroinflammation and elevates early markers of neurodegenerative disease. J Neuroinflammation. 2011:8:105.

40. Shou Y, et al. A review of the possible associations between ambient PM2.5 exposures and the development of Alzheimer's disease. Ecotoxicol Environ Saf. 2019:174:344-52.

41. Young T, Zychowski K, Denson JL, Campen MJ. Blood-brain barrier at the interface of air pollution-associated neurotoxicity and neuroinflammation. In: Role of inflammation in environmental neurotoxicity; 2018. p. 295-337.

42. Mumaw $\mathrm{CL}$, et al. Microglial priming through the lung-brain axis: the role of air pollution-induced circulating factors. FASEB J. 2016;30(5):1880-91.

43. Mostovenko E, et al. Nanoparticle exposure driven circulating bioactive peptidome causes systemic inflammation and vascular dysfunction. Part Fibre Toxicol. 2019;16(1):20.

44. Harkema JR, et al. Effects of concentrated ambient particles and diesel engine exhaust on allergic airway disease in Brown Norway rats. Res Rep Health Eff Inst. 2009:145:5-55. PMID:20198910.

45. Sioutas CP, Koutrakis P, Ferguson ST, Burton RM. Development and evaluation of a prototype ambient particle concentrator for inhalation exposure studies. Inhal Toxicol. 1995;7(5):633-44.

46. Walker JM. The bicinchoninic acid (BCA) assay for protein quantitation. Methods Mol Biol. 1994;32:5-8.

47. Maragkakis $M$, et al. DIANA-microT Web server upgrade supports Fly and Worm miRNA target prediction and bibliographic miRNA to disease association. Nucleic Acids Res. 2011;39(Web Server issue):W145-8.

48. Enright AJ, et al. MicroRNA targets in drosophila. Genome Biol. 2003;5(1):R1.

49. Lall $\mathrm{S}$, et al. A genome-wide map of conserved microRNA targets in C. elegans. Curr Biol. 2006;16(5):460-71.
50. Friedman RC, et al. Most mammalian mRNAs are conserved targets of microRNAs. Genome Res. 2009;19(1):92-105.

51. Wong N, Wang X. miRDB: an online resource for microRNA target prediction and functional annotations. Nucleic Acids Res. 2015;43(Database issue):D146-52.

52. Yu G, He QY. ReactomePA: an R/Bioconductor package for reactome pathway analysis and visualization. Mol BioSyst. 2016;12(2):477-9.

53. Assad N, et al. Metal-induced pulmonary fibrosis. Curr Environ Health Rep. 2018;5(4):486-98.

54. Bolt AM, et al. Tungsten targets the tumor microenvironment to enhance breast cancer metastasis. Toxicol Sci. 2015;143(1):165-77.

55. Chen KK, et al. Discontinuation of tyrosine kinase inhibitors in chronic myeloid leukemia with losing major molecular response as a definition for molecular relapse: a systematic review and meta-analysis. Front Oncol. 2019; 9:372.

56. Jaspers $M$, et al. Post-translational modification of the beta-subunit of the human fibronectin receptor. FEBS Lett. 1988;231(2):402-6.

57. Nozadi SS, et al. Use of Ages and Stages Questionnaires (ASQ) in a Navajo population: comparison with the U.S. normative dataset. Child Care Health Dev. 2019:45(5):709-18.

58. Rodosthenous RS, et al. Ambient particulate matter and microRNAs in extracellular vesicles: a pilot study of older individuals. Part Fibre Toxicol. 2016;13:13.

59. O'Toole TE, et al. Acrolein decreases endothelial cell migration and insulin sensitivity through induction of let-7a. Toxicol Sci. 2014;140(2):271-82.

60. Roush S, Slack FJ. The let-7 family of microRNAs. Trends Cell Biol. 2008; 18(10):505-16.

61. Wang $\mathrm{S}$, et al. MicroRNA let-7a regulates angiogenesis by targeting TGFBR3 mRNA. J Cell Mol Med. 2019;23(1):556-67.

62. Aragon M, et al. MMP-9-dependent serum-borne bioactivity caused by multiwalled carbon nanotube exposure induces vascular dysfunction via the CD36 scavenger receptor. Toxicol Sci. 2016;150(2):488-98.

63. Krauskopf J, et al. The human circulating miRNome reflects multiple organ disease risks in association with short-term exposure to traffic-related air pollution. Environ Int. 2018;113:26-34.

64. Hawkins PG, et al. Circulating microRNAs as biomarkers of radiation-induced cardiac toxicity in non-small-cell lung cancer. J Cancer Res Clin Oncol. 2019; 145(6):1635-43.

65. Sisto $R$, et al. Circulating microRNAs as potential biomarkers of occupational exposure to low dose organic solvents. Toxicol Rep. 2019;6:126-35.

66. Calderon-Garciduenas $L$, et al. Long-term air pollution exposure is associated with neuroinflammation, an altered innate immune response, disruption of the blood-brain barrier, ultrafine particulate deposition, and accumulation of amyloid beta-42 and alpha-synuclein in children and young adults. Toxicol Pathol. 2008;36(2):289-310.

67. Huang $\mathrm{K}$, et al. Predicting monthly high-resolution PM2.5 concentrations with random forest model in the North China Plain. Environ Pollut. 2018; 242(Pt A):675-83.

68. Tian $Y$, et al. Fine particulate air pollution and adult hospital admissions in 200 Chinese cities: a time-series analysis. Int J Epidemiol. 2019;48(4):1142-51.

69. Vodonos A, et al. Individual effect modifiers of dust exposure effect on cardiovascular morbidity. PLoS One. 2015;10(9):e0137714.

70. Campen MJ, et al. Cardiac and thermoregulatory effects of instilled particulate matter-associated transition metals in healthy and cardiopulmonary-compromised rats. J Toxicol Environ Health A. 2002;65(20): 1615-31.

71. Kodavanti UP, et al. The spontaneously hypertensive rat as a model of human cardiovascular disease: evidence of exacerbated cardiopulmonary injury and oxidative stress from inhaled emission particulate matter. Toxicol Appl Pharmacol. 2000;164(3):250-63.

\section{Publisher's Note}

Springer Nature remains neutral with regard to jurisdictional claims in published maps and institutional affiliations. 